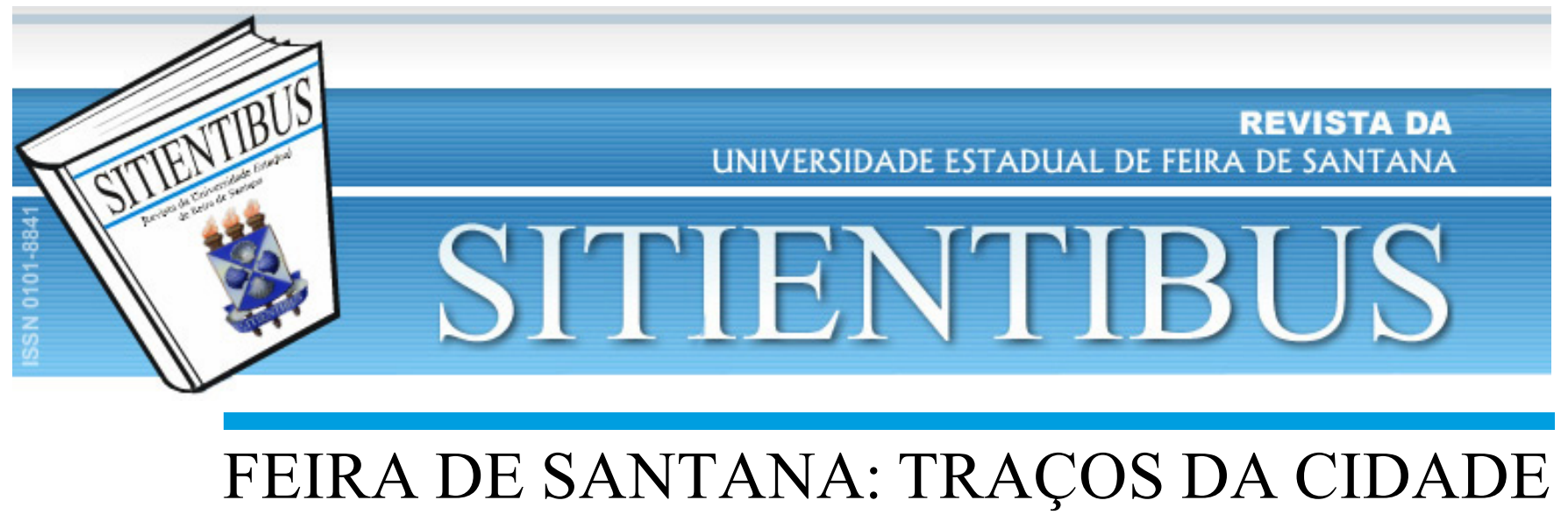

ARTIGO

\title{
AS BASES LEGAIS DA POLÍTICA DE HABITAÇÃO DE INTERESSE SOCIAL EM FEIRA DE SANTANA
}

\section{THE LEGAL BASES OF SOCIAL INTEREST HOUSING POLICY IN FEIRA DE SANTANA}

\section{PAULA SANTOS BRITO}

Mestre em Planejamento Territorial/UEFS. E-mail: paulabrito.ped@hotmail.com JANIO SANTOS

Doutor em Geografia/Professor Titular do DCHF-UEFS. E-mail: janiosantos@yahoo.com.br

\section{RESUMO}

A trajetória das bases legais que nortearam a política habitacional de interesse social em Feira de Santana, a partir da década de 1960, é o foco deste artigo, que sopesa tal reflexão articulada às mudanças e determinações que ocorreram na esfera federal, com destaque para os principais fundamentos que sustentaram o caráter institucional da luta por moradia no Brasil. Fundamentado por pesquisas bibliográficas e documentais, o texto apresenta breves apontamentos do conceito de política habitacional de interesse social, o panorama das ações implantadas no âmbito federal, bem como em Feira de Santana.

Palavras-chave: Feira de Santana, Política Habitacional, Interesse Social.

\section{ABSTRACT}

This article focuses on the trajectory of the legal bases that guided the housing policy of social interest in Feira de Santana from the 1960s. It is based on articulated reflections to changes and determinations that occurred in the federal sphere, highlighting the main foundations that supported the institutional character of the struggle for housing in Brazil. Based on bibliographic and documentary research, the text presents brief notes on the concept of housing policy of social interest, the panorama of actions implemented at the federal level and in Feira de Santana.

Keywords: Feira de Santana, Housing Policy, Social Interest.

\section{INTRODUÇÃO}

O Sistema de Habitação de Interesse Social foi sancionado pela Lei 11.124, de 16 de junho de 2005, Fundo Nacional de Habitação de Interesse Social (FNHIS) e o Conselho Gestor do FHNIS, após 13 anos de tramitação no Congresso. Esses elementos podem ser considerados com um dos principais instrumentos da Política Nacional da Habitação, haja vista que o desenho adotado na sua estrutura permite a atuação integrada dos três entes federados, em prol da redução do déficit habitacional, e possibilita que a moradia seja materializada enquanto direito e vetor de inclusão social (BRASIL, 2005).

Todavia, apesar do seu significado para a população e de seu expressivo aparato jurídico, composto por diversos instrumentos urbanísticos, estudos revelam que, até 2012, o Brasil apresentava um déficit habitacional estimado em 5,430 milhões de domicílios, dos quais 4,664 milhões (85,9\%) 
localizam-se em áreas urbanas; destaques para regiões Sudeste e Nordeste, com os maiores índices (FUNDAÇÃO JOÃO PINHEIRO, 2015).

Frente a esse cenário nacional, Feira de Santana, localizada a $107 \mathrm{~km}$ de Salvador, na Bahia, ganha destaque por ser um significativo entroncamento rodoviário, maior do Norte e Nordeste, além de articular três rodovias federais: BR 101, 116 e 324, e quatro estaduais: BA 052, 502, 503 e 504 (IBGE, 2017). Apesar do seu protagonismo regional, não diverge das constatações referentes à política de habitação do país, pois possui um déficit habitacional de 15.219 moradias, concentrado na área urbana (SOUZA, 2014).

Disso exposto, a trajetória das bases legais que nortearam a política habitacional de interesse social em Feira de Santana, a partir da década de 1960, é o foco principal deste artigo, que sopesa essa reflexão articulada às determinações que aconteceram na esfera federal, com destaque para os baldrames que sustentaram o caráter institucional da luta por moradia no Brasil.

Fundamentado por pesquisas bibliográficas e documentais, o texto é principiado por concisos apontamentos sobre a política habitacional de interesse social, após o que é apresentado um panorama das ações engendradas pelo governo federal. Para finalizar, são trazidos os alicerces da habitação de interesse social em Feira de Santana.

\section{O QUE SE ENTENDE POR POLÍTICAS DE HABITAÇÃO DE INTERESSE SOCIAL NO BRASIL}

A habitação não é uma necessidade que atinge apenas parcela da população, portanto, todos necessitam de moradia. Entretanto, percentual considerável de famílias usufrui de condições habitacionais precárias de infraestrutura, equipamentos, rede viária, saneamento etc. Ao transpor tal constatação para a história, fala-se do que se denominou por habitação de interesse social, ou seja, o termo utilizado desde a década de 1970, no Brasil, para fazer referência aos programas voltados para famílias de baixa renda e que desde então agências e instituições que lidam com tema o utilizam (ABIKO, 1995)

$\mathrm{Na}$ verdade, a literatura apresenta que o conceito de habitação de interesse social possui um conjunto de estratégias "[...] com uma dimensão física, mas também como resultado de um processo complexo de produção com determinantes políticos, sociais, econômicos, jurídicos, ecológicos, tecnológicos", voltadas às famílias inseridas em uma faixa de renda de zero a três salários mínimos, que vivem em condições insalubres, de aluguel e/ou em ocupações informais (ABIKO, 1995, p.05).

Apesar de utilizado com o mesmo significado, há diferenças entre "habitação de interesse social" e "habitação de mercado popular", pois a segunda refere-se à construções menores, por vezes, via autoconstrução, iniciativas próprias ou contratadas diretamente pelos usuários, sem estarem sujeitas aos mesmos critérios de planejamento e de implementação que os programas advindos do poder público (BONDUKI et al, 2003).

Abiko (1995, p.05) afirma que "[...] a habitação popular não deve ser entendida meramente como um produto e sim como um processo, com uma dimensão física, mas também como resultado de um processo complexo de produção com determinantes políticos, sociais, econômicos, jurídicos, ecológicos, tecnológicos". Implica que há um entendimento além dos aspectos legais, sobremodo porque o centro da problematização são as pessoas afetadas pela escassez da moradia e que sentem os seus efeitos.

Outrossim, cabe sinalizar que se pensa na política pública habitacional de forma integral e concreta, o que descarta qualquer tipo de fragmentação de decisões, e sim corresponsabilidades; ou seja, a política deve ser construída e consolidada por todos indivíduos que atuam sobre ela e/ou sofrem seus efeitos. Para Alves e Ferreira Filho $(2015$, p.6), se trata de uma política:

[...] que materializa o direito à moradia, passando,
sua elaboração e implantação, pela esfera
municipal, uma vez que o município, através das
suas respectivas câmaras municipais, é a entidade
pública responsável pelo estabelecimento de
leis que permitem orientar e ordenar a ocupação
urbana [...] Para tanto deve considerar as necessi-
dades regionais de cada município, pois cada
espaço territorial tem suas próprias características,
diferindo mesmo daqueles que se situam em seu
entorno, ou estão localizados muito próximos.

A política habitacional possui uma série de desdobramentos na esfera municipal, que tem responsabilidade na sua execução, já que se encontra em nível de maior alcance das especificidades da população e do território em torno dela. Trata-se de algo que não pode se encerrar em si, pois é transversal e multidimensional, haja vista que a cessão à unidade habitacional é apenas uma etapa das estratégias fundamentais, ou melhor, uma forma de atenuar expressões da questão social, inerentes à cidade.

Como elemento que compõe a história dessa política no Brasil, é possível reconhecer na criação da Fundação Casa Popular, através da Lei no 9218 de 10 de maio de 1946, o primeiro órgão público e, portanto, uma das primeiras respostas à questão da moradia, reivindicada pela população em âmbito nacional (PIRES; SILVA, 2014). Para Silva (1989, p.35), atuava como órgão de controle das massas, já que "[...] de sua moradia, muda com a conjuntura política; para isso, as classes populares foram atingidas pela ação do Estado através da Tríade: controle, repressão, exclusão".

Pouco tempo depois, segundo Bonduki (2008), foram criados o Banco Nacional de Habitação (BNH), em 1964, como resposta do Governo Militar a um país que crescia muito rápido, e o Sistema Financeiro de Habitação (SFH). Isso demonstra a intenção de investir em habitação a fim de alcançar resultados, sem maiores interferências das oscilações políticas ou até mesmo dependência de fonte 
de recursos instáveis. As ações do BNH e do SFH eram: coordenar a política, orientar a iniciativa privada, estimular a construção de casas populares, financiar a casa própria com um bom padrão habitacional e aumentar investimentos na indústria da construção civil (GOMES et al, 2003).

Para a maior parte da população, essa conjuntura era um "grande prejuízo", pois os investimentos destinados às habitações de interesse social eram pequenos, haja vista que, segundo Bolaffi (1977, apud MELO, 2013, p. 100), "[...] entre 1964 e 1977, o BNH aplicou Cr\$ 135 bilhões, financiando 1 milhão e 739 mil habitações, que foram destinadas, em sua maioria, a famílias com rendimentos superiores a 12 salários mínimos". Em contrapartida, à parcela da população que, de fato, alimentava o sistema restava o acesso às habitações precárias.

Quanto aos financiamentos, havia descompasso entre as variações nas parcelas e na política salarial, além de altas taxas de desemprego, o que afetava os recursos advindos do FGTS. Para Bonduki (2008), era uma produção com alto volume de recursos envolvidos para atender as demandas habitacionais, de forma que gerasse lucro e, todavia, não respondia às necessidades da população pobre.

Atrelada a essas fragilidades da política executada nas décadas de 1960 e 1970, se delimitava a configuração da cidade em que os pobres eram contemplados com modelos padrões de unidades sem considerar realidades locais, formando grandes conjuntos, distante dos centros, enquanto pequena parcela da população privilegiada tinha acesso às unidades maiores e individualizadas (SOUZA, 2008).

Com base em Bonduki (2008, p.74), a leitura que pode ser feita é de que a gestão não projetava a longo prazo, não pensava na sustentabilidade das suas decisões e, da mesma forma, eram unilaterais, sem o mínimo diálogo com os interessados, com aqueles que poderiam contribuir com sua efetividade, os quis alimentavam financeiramente os projetos. Se viam ações pontuais e com finalidades, por vezes, opostas as apresentadas no surgimento, já que poucas vezes atendiam aos que mais necessitavam de moradia.

Pautado por Bonduki (2008), esse quadro não foi produzido fora do contexto e dos interesses da época. A década de 1970 foi marcada por altos índices de pobreza e, nesse compasso, o número de mutuários inadimplentes crescia, o que forçou as companhias de habitação a reduzirem juros, pois a situação provocava recorrentes crises.

Frente à luta encampada pelos movimentos sociais pelas eleições diretas para Presidente e pela Constituinte, ao rombo do sistema financeiro gerado pela queda das prestações e a inadimplência, a situação se tornava cada vez mais favorável para que o $\mathrm{BNH}$ fosse alvo de muitas críticas e a situação começava a se tornar complicada. Em 1985, entretanto, meio ao novo cenário, surgiu uma grande expectativa de que seus gestores e sua estrutura fossem reformuladas em prol de uma nova política habitacional. Porém, por conveniência do novo governo, o órgão foi extinto pelo Decreto-Lei no 2.291/1986, sem encontrar resistências, pois havia se tornado uma das instituições mais odiadas do país. Após esse ato, a Caixa Econômica Federal (CEF) assumiu a política, com todas suas mazelas, e se tornou o agente financiador do SFH (BONDUKI, 2008).

$\mathrm{Na}$ busca pela integração nacional, se fortaleceu, na verdade, a minimização e a dependência do local em detrimento do nacional, acrescidas da crença de que a habitação se limita a estruturas físicas, construídas em massa, com recursos exclusivos do povo. Apesar disso, os resultados do BNH "[...] não são inteiramente desfavoráveis, pois foram construídas, após duas décadas, cerca de 4,5 milhões de unidades, com 33,5\% formalmente destinadas aos setores populares" (CARDOSO, 2006, p. 2).

Ao transferir atividades do BNH para CEF criou-se um ato questionável, porque tal ação transferiu a um banco comercial a condução da questão urbana, particularmente, a habitacional, uma instituição que, apesar de declarar caráter social, foi e sempre será permeada pela busca do equilíbrio financeiro, retorno de capital aplicado etc. Como forma de corroborar tais sinalizações, resgata-se em seus primeiros anos de atuação que a forma de se adaptar ao aparato legal foi transferir a inciativa privada os créditos para habitação popular, assim como diminuiu a capacidade dos estados e municípios de disciplinarem as questões habitacionais. Isso, mesmo com a existência de ministérios que supostamente teriam responsabilidades sobre as políticas urbanas e de habitação (AZEVEDO, 2007).

Com a Constituição de 1988, a responsabilidade da execução de ações voltadas à habitação passou a ser de todos entes federados, excelente novidade, já que se destinava maior força ao poder local, que se encontra mais próximo das comunidades. Diante essa decisão, ocorreu tendência a descentralizar programas habitacionais nas décadas seguintes (BONDUKI, 1998).

Não se pode negligenciar que o Estado progrediu quanto às políticas habitacionais, principalmente, porque foram grandes os avanços legais que possuem poder de assegurar aos mais necessitados o direito à moradia. Entretanto, alguns ganhos não foram proporcionais a resolutividade das questões, ao mesmo tempo que o mercado imobiliário e da construção civil sempre estavam a ser beneficiados.

Importante sinalizar que, mesmo não tão expressivas, para mudanças consideradas estruturais, as alterações provocadas pela Constituição de 1988 abriram possibilidades, na década de 1990, para diversas experiências municipais que atendessem às demandas por habitações de interesse social. Isso oportunizou tornar a execução do direito à moradia pouco homogêneo e padronizado, sem desconsiderar que, ao mesmo tempo, havia pouca articulação com outras políticas, pois não existia uma norma nacional sistematizada e clara.Por isso, a tendência foi cada gestor municipal atuar em prol de programas e projetos próprios (SOUZA, 2008). 
Ao longo tempo que Collor (1990-1992) esteve no poder, crises existentes desde a extinção do BNH foram agravadas, principalmente porque as mudanças no SFH foram superficiais. Todavia, as decisões podem ser caracterizadas "[...] por processos em que os mecanismos de alocação de recursos obedeceram preferencialmente a critérios clientelistas ou ao favorecimento de aliados do governo federal" (EMILIANO, 2006, p. 22). Além disso, cabe dizer que, sobre a habitação popular, esse governo exerceu a "[...] banalização da política, com sua dissociação das atividades de saneamento e desenvolvimento urbano" e Ihe imprimiu caráter distributivo (AZEVEDO, 2007, p.97).

Com o impeachment de Collor e a posse de Itamar Franco, a gestão da habitação foi direcionada ao Ministério do Bem-Estar Social, que passou a exigir a participação de conselhos, compostos por pessoas das comunidades, dos governos locais e a contrapartida financeira desses últimos aos investimentos da União. Essas alterações "[...] aumentaram significativamente o controle social e a transparência da gestão dos programas em questão, e constituíram-se em ponto de inflexão importante na condução das políticas públicas na área de habitação popular" (SANTOS, 1999, p. 21).

Também nesse governo foi lançado o Programa Habitar Brasil, direcionado aos municípios com mais de 50 mil habitantes, e o Morar Município, voltado aos de menor porte, ambos com o objetivo de atuar junto as famílias de baixa renda e/ou que viviam em áreas de risco. Os dois programas tinham verbas previstas pelo governo federal, sendo uma parte do orçamento da União e a outra de recursos arrecadados pelo Imposto Provisório sobre Movimentações Financeiras (IPMF). Para ter acesso a essas rubricas, exigiu-se a criação de um conselho (estadual ou municipal) e de um fundo, para o qual seriam direcionados os recursos (AZEVEDO, 2007).

Enquanto características do público alvo e de sua participação, deveriam ser proprietários dos terrenos e, dentre as diversas diretrizes dos programas, a construção ou melhoria de moradia deveria seguir o regime de "ajuda mútua" ou "autoajuda", acompanhada pela assistência técnica do ente federado. Tal assessoria poderia ser paga com até $5 \%$ dos recursos financiados pela União (AZEVEDO, 2007).

Pouco tempo depois, o Governo de FHC apresentou a nova conjuntura na política habitacional. Em suas ações, extinguiu o Ministério do Bem-Estar Social e criou a Secretaria de Política Urbana (SEPURB). No âmbito do Ministério de Planejamento e Orçamento, é possível reconhecer reformas mais efetivas no setor habitacional e o lançamento de novos programas e aprimoramento de outros (SOUZA, 2005).

Enquanto Programa destaque, tinha-se o Carta de Crédito, voltado às famílias com renda até 12 salários mínimos, que poderiam usar os recursos para comprar casa nova, usada ou lote, assim como material para construir ou ampliar. Havia também outra forma de adquirir casas através de grupos associados, enquanto Organizações Não Governamentais (ONGs), condomínios, associações etc. Os programas Pró-Moradia e o Habitar-Brasil também foram financiados pelo FGTS e, em contrapartida, por estados e municípios, voltados para famílias de até três salários mínimos, que viviam em condições insalubres ou de forma inadequada (SOUZA, 2005).

Na gestão de FHC, após doze anos de tramitação, foi aprovado o Estatuto da Cidade, que regulamentou os artigos 182ㅇ e 183 da Constituição Federal de 1988 e estabeleceu as diretrizes gerais da política urbana (BRASIL, 2001). Para Souza (2005), os resultados desse governo comprovaram que, apesar dos investimentos, as velhas práticas do SFH não perderam a natureza excludente, sendo aplicados em volume considerável para alimentar diretamente o setor imobiliário e/ou da construção.

O ex-presidente Luís Inácio Lula da Silva constituiu marcos para a história da política urbana: a criação do Ministério das Cidades, em 2003 (BRASIL, 2003); foi aprovada a Política Nacional de Habitação, em 2005; foram sancionados, através da Lei 11.124/05, o Sistema Nacional de Habitação de Interesse Social (SNHIS) e o Fundo Nacional de Habitação de Interesse Social (FNHIS); e se instituiu o Conselho Gestor do FNHIS, em 2005, primeiro projeto de lei de iniciativa popular (BRASIL, 2005).Mesmo com avanços, Bonduki (2008) resgata traços evidentes desde a extinção do BNH: apesar da criação do Ministério das Cidades, a gestão dos recursos voltados a habitação ainda é da CEF, ou seja, financiamentos e gestão dos projetos ficam a critério dessa instituição.

Foi o governo de Lula que criou o Programa Minha Casa Minha Vida (PMCMV), inédito na história da política habitacional no país, sobretudo pelo volume dos investimentos previstos, 34 bilhões (ARANTES; FIX, 2009). O que não implica dizer que o mesmo não tenha atendido aos interesses do capital, de forma ampliada, apesar do ex-presidente contradizer isso. Foi criado com o objetivo de estimular a produção e aquisição de novas unidades habitacionais, entre famílias com renda de 0 a 10 salários mínimos (subdividas em faixas), além de requalificar imóveis urbanos e realizar reforma de unidades rurais. Aliado a isso, surgiu com a proposta de movimentar o mercado da construção civil e gerar mais empregos no ramo (HIRATA, 2009).

Esse contexto foi fomentado, sobretudo, pelo alto déficit habitacional existente no país, a época. O Ministério das Cidades diagnosticou que, em 2008, superavam cinco milhões de residências, estando $89 \%$ do déficit na faixa 1 , com renda de até três salários mínimos e, por consequência, aos quais seria destinada maior parte das unidades. Em momento posterior, houve alteração na composição dessa faixa e também fariam parte dos beneficiados famílias que possuíssem renda de até $\mathrm{R} \$ 1.600,00$ (BRASIL, 2011).

Segundo Arantes e Fix (2009, p. 1), identifica-se que, quanto aos investimentos, houve injeção direta de recursos na iniciativa privada, com a alegação de existência de dificuldades, por parte dos munícipios, em aplicar os recursos, além de que, naquele momento, se fazia necessária à reversão da crise. 


\section{POLÍTICA DE HABITAÇÃO DE INTERESSE SOCIAL NA CIDADE DE FEIRA DE SANTANA}

Aliados ao contexto nacional, as décadas de 1960 e 1970 foram marcos, pois nesses anos é possível identificar acontecimentos que influenciaram o setor da habitação de Feira de Santana, tais como a criação da Habitação e Urbanização do Estado da Bahia S/A (URBIS), em 1965, empresa de sociedade mista voltada ao planejamento, estudos e execução da política habitacional na Bahia.

No campo das legislações, sinaliza-se a Lei no 613, de 29 de abril de 1969, na qual o prefeito Newton Falcão da Silva foi autorizado a receber indenização da URBIS (NCr\$ $113.629,31)$ pela construção de 19 casas populares. Parte desse valor foi pago no ato da assinatura de escritura pública de rerratificação da doação e a outra em prestações mensais (FEIRA DE SANTANA, 1969). Tal lei revela a presença do munícipio perante ações da URBIS, através de atuação na construção de unidades habitacionais (SANTO, 2012). Porém, verifica-se que, das 2.202 casas, distribuídas entre 3 conjuntos (Feira I II e III), atualmente o bairro Cidade Nova e o subairro Jomafa, o governo construiu apenas 19.

Na década seguinte, destaca-se a Lei $\mathrm{n} \cong 703$, de 09 de junho de 1971, a qual autorizou a abertura de crédito para pagamento das parcelas finais de empréstimo tomado junto ao Sistema Federal de Habitação e Urbanismo (SERFHAU), para financiar o Plano de Desenvolvimento Local Integrado (PDLI), publicado em 1968 (FEIRA DE SANTANA, 1971). Para Santo (2011, p.03), a meta era "[...] corrigir as distorções, ordenar e disciplinar o uso e ocupação do solo urbano".Esse plano, apesar de executado no governo de João Durval, teve como propulsor seu antecessor, o prefeito Joselito Amorim (19641967), através do decreto № 1.494, de 21 de outubro de 1964.

Enquanto contribuição para a política de habitação, o PDLI foi marco na história do planejamento urbano no Brasil e na América Latina. A intenção de João Durval em executar o projeto de modernização da cidade, que visava o "desenvolvimento", ganhou contorno mais institucional quando ocorreu a instalação do Centro Industrial do Subaé, em 1970, no bairro Tomba, região sul da cidade (MONTEIRO, 2009).

Percebe-se o quanto a intitulada "necessidade" de integrar-se à modernização pela qual passava a Bahia, em função da instalação das unidades industriais, movimentou, no período, diversos setores de Feira de Santana. Da mesma forma, ocasionoua concentração de "bairros planejados", voltados sobretudo para trabalhadores, no entorno do CIS: "[...] de norte a sul da cidade, cujas casas eram financiadas tanto pelo Estado, quanto por inciativa privada", muitos deles distantes do centro da cidade (MUNIZ, 2011, p.51).

No ano 1977, foi sancionada a Lei no 825 , a qual apresenta a criação do Plano Municipal de Habitação Popular (PLANOLAR) $^{1}$ e a Diretoria de Habitação (FEIRA DE SANTANA, 1977). Isso foi fruto dos primeiros governos de Colbert
Martins da Silva (MUNIZ, 2011) e possuía "[...] finalidade de proporcionar às famílias de baixa renda, o acesso a casa própria, [...] construídas na área urbana do município pelo sistema de mutirão" Caberia ao município prover o terreno, obras de infraestrutura, equipamentos como escolas e postos de saúde; assistir cada conjunto com linha de transporte própria; além de comprar materiais para a construção que deveriam ser pagos, pelos beneficiários, em prestações entre 10 e $15 \%$ do salário mínimo regional. São apresentados também critérios para se tornar beneficiário, sendo esses previamente analisados por uma comissão composta por três membros, sendo um "[...] membro nato, representante eleito do conselho de moradores, logo após a criação deste" (FEIRA DE SANTANA, 1977).

Pelo que se verifica na lei, o plano contempla a multidimensionalidade do habitar, ou melhor, institui-se como direito: oferece condições básicas para a vida saudável e garante a participação popular, com o envolvimento direto de beneficiários. Além disso, foi instituído num momento em que Feira de Santana crescia demograficamente. Apesar de bem formatado, no que tange a lei, o PLANOLAR, na sua execução, sofreu resistências e críticas, não somente naquele período, por compor um conjunto de políticas paternalistas, que construiu unidades habitacionais em áreas periféricas da cidade de Feira de Santana, réplicas das práticas dos órgãos executores da política de habitação desenvolvidas em outras cidades baianas, além de causar prejuízo à saúde dos moradores, quando construiu conjuntos próximos ao CIS (MUNIZ, 2011).

A década de 1980, quanto à política de habitação do município, foi marcada pela construção de novos conjuntos, através de órgãos como a URBIS e o Instituto de Orientação às Cooperativas Habitacionais (INOCOOP). O último contemplava famílias entre cinco a oito salários mínimos, em sua maioria, funcionários públicos, militares e profissionais liberais (SANTO, 2012). Nessa década, nas gestões Colbert Martins da Silva, João Durval da Silva e José Falcão (1983-1987, MDB; 1997, PFL), o município de Feira de Santana aumentou de modo expressivo a população, sobretudo a urbana.

Em 1991, através da Lei no 1.497, Colbert Martins da Silva, em seu segundo mandato, autorizou a criação da Companhia Municipal de Urbanização e Habitação (COMUHAB), vinculada à política nacional, que era "[...] organizada sob forma de Sociedade de Economia Mista e criada sob tempo indeterminado" (FEIRA DE SANTANA, 1991). Surgiu na lei a Secretária de Habitação Popular e Desenvolvimento Comunitário, criada anteriormente, face à promulgação da Lei no 1349/1990, com o objetivo de "[...] traçar, orientar, executar e fiscalizar as políticas municipais de habitação e desenvolvimento comunitário" (FEIRA DE SANTANA, 1990).

Tal criação revela diferente condução da gestão anterior de Colbert Martins da Silva, quando instituiu o PLANOLAR. Com a criação da COMUHAB, demonstrou-se um viés neoliberal, quando incrementa a execução da política

\footnotetext{
${ }^{1}$ Segundo Muniz (2011, p 56-57.), o PLANOLAR “[...] foi órgão municipal com o objetivo de suprir a demanda de habitação dos que não possuíam renda fixa através da doação de lotes e, em alguns casos, empréstimo de material básico para a construção das casas. Esse órgão foi um marco na política de habitação, a ponto de ter instituído lei específica".
} 
com sociedade mista que passou a ter, dentre outros fins, a execução e financiamento de programas habitacionais. Compreende que, nesse momento, logo após o país aprovar a chamada "Constituição Cidadã", com delimitações claras do papel do Estado, um governo instituir vínculos com uma companhia que poderia, inclusive, adquirir empréstimos junto ao munícipio, deve ser interpretado como uma decisão um tanto quanto questionável e com viés muito mais mercadológico, que, necessariamente, uma política voltada para suprir demandas sociais.

Com a lei no 1614, de agosto de 1992, último ano do governo de Colbert Martins da Silva, a Câmara de Vereadores de Feira de Santana instituiu um Plano Diretor, após a obrigatoriedade prevista na Constituição de 1988, para municípios com mais de 20 mil habitantes (FEIRA DE SANTANA, 1992). Todavia, até os dias atuais, ainda não foi instituiu um novo plano de desenvolvimento urbano, ainda que tenha sido elaborado o Plano Diretor de Desenvolvimento Urbano de Feira de Santana (PDDU), em 2000, o qual não foi instituído; e em 2006 tenha sido finalizada a versão atualizada do Plano Diretor de Desenvolvimento Municipal de Feira de Santana, também não aprovado pela Câmara.

Quanto ao Plano de 1992, pautado no Capítulo II, nos artigos $182^{\circ}$ e $183^{\circ}$ da Constituição Federal de 1988, notase consonância em seu conteúdo quanto à função social da propriedade e à participação popular. Sinaliza também aspectos não contidos na Constituição, como a concessão real de direito de uso para áreas ocupadas por pessoas com baixa renda e assegura assistência técnica e jurídica aos mesmos (FEIRA DE SANTANA, 1992). Sobre instrumentos atuais, como parcelamentos ou edificação compulsórias, IPTU progressivo e desapropriação, esses não aparecem no texto, até porque só serão regulamentados a partir da promulgação do Estatuto da Cidade, em 2001.

Através do decreto no 6563, de 2002, sancionado no primeiro governo do prefeito José Ronaldo de Carvalho, foi regulamentada a lei no 2038, de 1998, na qual o poder público autoriza a doação de domínio útil (direito de usar, sem transmissão da posse) às pessoas físicas, para fim de habitação. Nesse documento, foram definidos princípios para essa prática, tais como proibição de alienação, salvo em casos de óbitos e obrigação de lavrar a escritura em nome da mulher; foram sinalizados também o perfil das pessoas que poderiam ser beneficiárias, bem como definiu-se o tamanho do lote (FEIRA DE SANTANA, 2002).Nessa lei, se reconhecem questões de gênero, o que consolida que tais lutas sociais também eram travadas em Feira de Santana, na época.

Outra informação que surge, dentre os critérios dos beneficiários, é que poderiam ser favorecidas pessoas que fizeram parte do PLANOLAR; ou seja, registra que, em 2002, o órgão não mais existe, da mesma forma que sinaliza a inexistência de uma secretaria de habitação, mas, de um departamento na Secretaria Municipal de Desenvolvimento Social, estrutura que originou o atual formato, no que se refere ao organograma.
Em 2003, a Lei no 2426 avançou na mesma direção em relação à doação de terras, porém de forma específica e ampla "[...] para a implantação do programa de subsídios à habitação de interesse social". Tal ação foi realizada em prol da implantação do núcleo habitacional do Programa de Subsídio de Habitação de Interesse Social (PSH), no bairro Aviário, composto por famílias de baixa renda. Em 2004, a Lei no 2501 acresceu dispositivo à lei no 2477, do mesmo ano, que trata sobre a doação de terras a pessoas físicas para fins de habitação (FEIRA DE SANTANA, 2003; 2004a; 2004b).

Em 2007, após a criação do Sistema Nacional de Habitação de Interesse Sociale de seus componentes, através da Lei no 2801, criou-se o Fundo Municipal de Habitação de Interesse Social de Feira de Santana e instituiu-se o Conselho Gestor do Fundo, isso independente da aprovação do plano diretor. Esse ato foi importante para a população de baixa renda, pois favoreceu a habilitação de Feira de Santana para o recebimento de recursos do Sistema Nacional e, portanto, ampliou o poder de atuação frente ao déficit habitacional existente (FEIRA DE SANTANA, 2007).

No ano de 2009, a lei no 2987 enquadrou como Zona Especial de Interesse Social (ZEIS) todas as áreas representadas pelas glebas dos empreendimentos vinculados ao PMCMV. Com esse Programa, a cidade contou com um grande número de contratações de unidades,com tipologia vertical, algo não inédito, mas que veio num momento que substancia qualitativamente o direito à moradia (FEIRA DE SANTANA, 2009b).

Em 2011, com Lei a no 64, foi instituído o primeiro Plano Habitacional de Interesse Social do Município de Feira de Santana, com conteúdo bastante limitado quanto aos elementos essenciais que deveriam compor uma proposta dessa natureza, tais como diagnóstico bem elaborado e áreas claras para implantação de políticas habitacionais (FEIRA DE SANTANA, 2011). Não foram encontrados indícios ou motivos do porquê lhe foi dada essa natureza assaz frágil. Entretanto, se forem considerados o contexto nacional da época e os prazos legais exigidos para recepção de recursos para fins de políticas habitacionais, a leitura que se faz é de que, provavelmente, foi elaborado um mero instrumento para cumprir as exigências do governo federal, no sentido de viabilizar verbas para projetos e programas habitacionais.

Entretanto, em março 2012, a Lei no 65 apresenta um plano melhor elaborado, em relação ao de 2011, amplamente referenciado pela Constituição Federal de 1988, pela Política Nacional de Habitação, pelo Estatuto da Cidade, pela Lei Orgânica Municipal, dentre outras referências legais. Também discorre sobre as ZEIS, conceitos e delimitações no município, e sobre a Política Municipal de Habitacional, com suas metas e objetivos (FEIRA DE SANTANA, 2012a). A Lei no 3328, do mesmo ano, dispõe sobre o Conjunto Ayrton Senna da Silva, classificando-o como ZEIS. O que torna isso importante é o fato de que esse conjunto concentrava o maior número de contratação de empreendimentos (entregues, construídos ou em construção) do PMCMV, o que totalizava, no período, 19 conjuntos habitacionais (FEIRA DE SANTANA, 2012b). 
Tardiamente, a Lei no 3522, no ano de 2015, dispõe sobre criação do Conselho das Cidades, órgão colegiado, de caráter consultivo e propositivo (FEIRA DE SANTANA, 2015). Contudo, desde a sua criação até o presente, 2017, não tem tido papel ativo frente às demandas da cidade, aspectos que não serão abordados neste texto.

\section{CONSIDERAÇÕES FINAIS}

Chama-se atenção para o fato de que Feira de Santana é uma cidade que não preserva bem sua memória e não reconhece (ou reconhece muito pouco) a importância de preservar fontes de dados e informações sobre as gestões anteriores, bem como deixá-las acessíveis para compreensões sobre processos e políticas urbanas realizadas.

Com base na história da política habitacional do Brasil e de Feira de Santana, observa-se que a realidade local não destoa da nacional. Ou seja, ocorre a reprodução ciclos de descontinuidades no que se refere ao direito à moradia, através de programas, políticas e projetos que estão aquém da execução de propostas concretas e sustentáveis, com vistas a alcançar os objetivos reais das políticas habitacionais.

Ao retomar o panorama das políticas habitacionais, do Brasil e de Feira de Santana, confirma-se o quanto os gestores necessitam ser atuantes na garantia do direito à moradia, algo cobrado pela sociedade, haja vista os impactos gerados quando esse não é atendido de forma efetiva. Da mesma forma, se faz relevante potencializar o papel dos municípios, da gestão local, não somente na execução, como também na formulação de políticas urbanas, com a ampla participação da população.

Apesar de não se reconhecer na história da cidade estudos que demonstram grandes avanços na execução de programas habitacionais, na garantia integral do direito à moradia, Feira de Santana, através do PMCMV, foi contemplada com várias unidades habitacionais de interesse social. Nesse sentido, cabe aos gestores pensar, não apenas sobre a implantação de unidades, mas sobretudo a requalificação das já existentes, com vista, através da execução continuada, a engendrar ações que promovam, sobretudo, o fortalecimento comunitário, a integração das famílias à rede de serviços das suas novas moradias e a construção de novos equipamentos públicos para atender o aumento da demanda. Isso, sem que essas ações estejam exclusivamente vinculadas a programas federais ou que tenham sua existência restrita a rubricas limitadas e sem perenidade.

\section{REFERÊNCIAS}

ABIKO, A. K. Introdução à gestão habitacional. São Paulo: Politécnica USP, 1995

ALVES, A. L de L.; FERREIRAFILHO, H. R. A política habitacional na construção do plano diretor municipal e sua importância para a mitigação de impactos ambientais em Belém capital do estado do Pará. Contribuciones a las Ciencias Sociales.
Málaga, 2015. Disponível em:<http://www.eumed.net>. Acesso: 08 ago. 2015.

ARANTES, P. F.; FIX, M. Como o governo Lula pretende resolver o problema da habitação. Alguns comentários sobre o pacote habitacional Minha Casa, Minha Vida. Correio da cidadania, v. 30, 2009. p. 01-25.

AZEVEDO, S. Habitação social nas metrópoles brasileiras: Uma avaliação das políticas habitacionais em Belém, Belo Horizonte, Porto Alegre, Rio de Janeiro e São Paulo no fim doséculo XX. In: Coleção Habitare. Vol. 1 - Cap1. Porto Alegre, ANATAC, 2007.

BONDUKI, Nabil. Origens da habitação social no Brasil: Arquitetura Moderna, Lei do inquilinato e Difusão da Casa Própria. São Paulo: Estação da Liberdade, 1998.

. et al. São Paulo: Plano Diretor Estratégico. Cartilha de Formação. São Paulo: Caixa Econômica Federal, 2003. 87 p. Política habitacional e inclusão social no Brasil: revisão histórica e novas perspectivas no governo Lula. Revista Arquitetura e Urbanismo. n. 01, p. 70-104, 2008, Disponível em: <http:usjt.br/arq.urb/> acesso: 05 mai. 2015. BRASIL, Presidência da República do. Constituição da República Federativa do Brasil. Brasília: Senado Federal, 1988.

Estatuto da Cidade. Lei 10.257 , de 10 de julho de 2001. Regulamenta os arts. 182 e 183 da Constituição Federal, estabelece diretrizes gerais da política urbana e dá outras providências. Disponível em: <http://www.planalto. gov.br>. Acesso 10 mai 2016.

Lei no 11.124, de 16 de junho de 2005. Dispõe sobre o SNHIS, cria o Fundo FNHIS e institui o Conselho Gestor do FNHIS. Disponível em: <http://www.planalto.gov. br>. Acesso em: 05 mai. 2015

Ministério das Cidades. Déficit Habitacional no Brasil 2008. Brasília, DF: Ministério das Cidades, 2011.

CARDOSO, Adauto Lucio. Política habitacional no Brasil: balanço e perspectivas. Rio de Janeiro: UFRJ, 2006.

EMILIANO, E. de O. Legislação para habitação de interesse social Estudo de caso do município de Campinas. $100 \mathrm{f}$. Dissertação (Mestrado em Urbanismo)-Centro de Ciências Exatas, Ambientais e de Tecnologias. PUC, Campinas, 2006.

FEIRA DE SANTANA. Lei 613, de 29 de abril de 1969. Autoriza o prefeito municipal a receber indenização da habitação e urbanização da Bahia S/A-URBIS, na forma que especifica. Disponível em: <http://leismunicipais.com.br> Acesso em: 20 fev. 2016.

Lei 825, de 15 de agosto de 1977. Cria o Plano Municipal de Habitação Popular- PLANOLAR e a diretoria de habitação social, e dá outras providências. Disponível em: <https://leismunicipais.com.br>acesso 25 fev. 2016.

Lei no 1614, agosto de 1992. Dispõe sobre o plano diretor de desenvolvimento do munícipio de Feira de Santana, e dá outras providências. Disponível em: <https:// leismunicipais.com.br>. Acesso 25 fev. 2016. 
. Decreto 6563, 29 de abril de 2002. Regulamenta Lei no 2038 de 07 de dezembro de 1998. Regulamenta Lei 2038 de 07 de dezembro de 1998 que autoriza o poder executivo a doar áreas de terra a pessoas física para fim de habitação, e da outas providências. Disponível em: <http:// leismunicipais.com.br>. Acesso 25 fev. 2016.

. Lei 2426, 07 agosto de 2003b. Autoriza a doação de áreas de terra para implantação do Programa de Subsídios à Habitação de Interesse Social-PSH e dá outras providências. Disponível em: <http://leismunicipais.com.br>. Acesso 25 fev. 2016.

Lei no 2501, de 18 de maio de 2004a. Acrescenta dispositivo a lei no 2477, de 17 de março 2004, que "autoriza o poder executivo a doar áreas de terra a pessoas físicas para fins de habitação e dá outras providências". Disponível em: <http://leismunicipais.com.br>. Acesso 25 fev 2016.

. Lei complementar no 018, de 08 de julho de 2004b. Define o perímetro urbano, delimita os bairros da cidade de Feira de Santana e dá outras providências. Disponível em: <http://leismunicipais.com.br>. Acesso 25 fev 2016.

Lei 2801, 13 de junho de 2007.Cria o FMHISFS institui o Conselho Gestor do FMHISFS e dá outras providências. Disponível em: <http://leismunicipais.com.br>. Acesso 25 fev 2016.

. Lei 2987, de 29 de junho de 2009a. Dispõe sobre o enquadramento e delimitação das áreas destinadas a implementação do programa minha casa minha vida como ZEIS e define os parâmetros urbanos para o programa para a renda de 0 a 3 salários mínimos. Disponível em: <http:// leismunicipais.com.br>. Acesso 25 fev 2016.

. Lei no 64 , de 16 de dezembro de 2011. Institui o Plano Habitacional de Interesse Social do município de Feira de Santana, e dá outras providências. Disponível em: Disponível em: <http://leismunicipais.com.br>. Acesso 25 fev 2016.

. Lei no 65, de 15 de março de 2012a. Institui o Plano de Habitação de Interesse Social do município de Feira de Santana, e dá outras providências. Disponível em: Disponível em: <http://leismunicipais.com.br>. Acesso 25 fev 2016.

Lei no 3328, de 14 de junho de 2012b. Dispõe sobre a delimitação da área do Conjunto Ayrton Senna da Silva, classificando a como ZEIS, e dá outras providências. Disponível em: <http://leismunicipais.com.br>. Acesso 25 fev. 2016.

Lei no 3522, de 02 de abril de 2015. Dispõe sobre a criação do Conselho da Cidade de Feira de Santana (CONCIDADE), e dá outras providências. Disponível em: <http:// leismunicipais.com.br>. Acesso 25 fev 2016.

FORTINI, C. Plano Diretor - temas polêmicos. Discussão sobre a iniciativa para sua elaboração. A imperiosidade de Plano Diretor para apurar o cumprimento da função social da propriedade. In: Revista de Direito Municipal, no 4, n. 7, jan./mar. 2003
FUNDAÇÃO JOÃO PINHEIRO. Déficit habitacional no Brasil 2011-2012. Belo Horizonte: Centro de Estudos Políticos e Sociais, 2015.

GOMES, R. de C. da C et al. Política habitacional e urbanização no Brasil. Revista de Geografía y Ciencias Sociales, v. VII n. 146, p. 83 2003. Disponível em: <http://www.ub.edu/ geocrit/sn/sn-146(083).htm> Acesso em 08 ago. 2014.

HIRATA, F. Minha Casa, Minha Vida: Política habitacional e de geração de emprego ou aprofundamento da segregação urbana? Aurora, São Paulo, v 2, n 2, 2009, p.1-11.

INSTITUTO BRASILEIRO DE GEOGRAFIA E ESTATÍSTICA (IBGE). Redes e fluxos do território: ligações rodoviárias e hidroviárias, 2016. Rio de Janeiro: 2017. Disponível em: <https://www. ibge.gov.br/>. Acesso em: 27 out. 2017.

MELO, W. F. de. A ditadura, a questão da moradia e a modernização excludente: Roberto Campos em defesa do Sistema Financeiro da Habitação, Verinotio.n. 17, p. 91-104, 2013. Disponível em: <http://www.verinotio.org/>. Acesso em: 08 ago. 2015.

MUNIZ, M. da S. Em busca da experiência: paternalismo, lutas e autonomia dos trabalhadores feirenses (1977-1991). 2011. 199f. Dissertação (Mestrado em História), Programa de Pós-Graduação em História, UEFS, Feira de Santana, 2011. PIRES, V. da R.; SILVA, L.A.M. da. Estado e Política Pública Habitacional no Brasil: alguns apontamentos In: SIMPÓSIO DE DESENVOLVIMENTO, TECNOLOGIAS E SOCIEDADE, IV, Anais. Universidade Federal de Itajubá, 2014. p. 1-10.

SANTO, S. M. A expansão urbana, o estado e as águas em Feira de Santana/Bahia (1940-2010). 2012,275f. Tese (Doutorado em Arquitetura e Urbanismo) - Faculdade de Arquitetura, Universidade Federal da Bahia, Salvador, 2012. . et al. Planejamento urbano de Feira de Santana (BA): comparação entre os planos diretores de 1968 e 2000. Revista Geográfica da América Central. Costa Rica. Número Especial EGAL, 2011. p. 1-17, 2011.

SANTOS, C. H. M. Políticas Federais de Habitação no Brasil.In: Textos para discussão, IPEA, no 654, p. 1-32, jul. 1999.

SILVA, M. O Se. Política Habitacional Brasileira: verso e reverso. São Paulo: Cortez, 1989.

SOUZA, A. G et al. Limites do Habitar: Segregação e exclusão na configuração urbana contemporânea de Salvador e perspectiva no final do século XX. Salvador: Edufba, 2008.

SOUZA, Lena Mara de. Análise comparativa das políticas habitacionais nos governos Fernando Henrique Cardoso e Luis Inácio Lula da Silva. 164 f. Dissertação (Mestrado Profissional em Gestão de Políticas Públicas) - Centro de Educação de Ciências Jurídicas, Políticas e Sociais.Univali, 2005.

SOUZA, M. de L. C. Necessidades habitacionais nos municípios do território de identidade portal do sertão da Bahia. In: SIMPÓSIO CIDADES MÉDIAS E PEQUENAS DA BAHIA, IV. Anais, Barreiras, SEl. Salvador, 2014. 